\title{
Foliar application of 28-homobrassinolide mitigates salinity stress by increasing the efficiency of photosynthesis in Brassica juncea
}

\author{
Mohammed Nasser Alyemeni ${ }^{1}$, Shamsul Hayat ${ }^{1,2}$, Leonard Wijaya and Abdullah Anaji ${ }^{1}$
}

Received: 4 November, 2012. Accepted: 29 June, 2013

\begin{abstract}
Prior to sowing, seeds of Brassica juncea Czern and Coss cv. Varuna were soaked in water (controls) or in 50, 100 or $150 \mathrm{mM}$ of sodium chloride $(\mathrm{NaCl})$ for $6 \mathrm{~h}$. The resulting plants, at 15, 30 and 45 days after sowing (DAS) were either not treated (controls) or were treated with aqueous solutions of the hormone 28-homobrassinolide (HBL), which was applied to their foliage in concentrations of $10^{-10}, 10^{-8}$ or $10^{-6} \mathrm{M}$. The concentration of $\mathrm{NaCl}$ showed an inverse correlation with the activity of nitrate reductase (EC 1.6.6.1), the activity of carbonic anhydrase (EC 4.2.1.1), chlorophyll content at $60 \mathrm{DAS}$, the rate of photosynthesis at $60 \mathrm{DAS}$, and seed yield at 140 DAS (at harvest), all of which decreased in parallel with increases in $\mathrm{NaCl}$ concentration. However, treatment with HBL attenuated those decreases and neutralized the ill effects of salinity stress, completely at the lowest $\mathrm{NaCl}$ concentration and partially at the higher $\mathrm{NaCl}$ concentrations. The seed yield of the crop can be increased by the foliar application of HBL, even under conditions of salinity stress.
\end{abstract}

Key words: Carbonic anhydrase, chlorophyll, homobrassinolide, nitrate reductase, seed yield

\section{Introduction}

Soil salinity is a major environmental problem and poses an ever-increasing threat to the growth of plants and their productivity (Koca et al. 2007). In the affected plants, soil salinity reduces the photosynthesis rate by decreasing the level of chlorophyll (Chaves et al. 2009), as well as inhibiting Rubisco activity and causing the closure of stomata, thereby decreasing partial pressure of $\mathrm{CO}_{2}$ (Soussi et al. 1998). Even $\mathrm{NaCl}$ alone decreases the level of nitrate reductase (Aslam et al. 1984), which is the primary enzyme involved in the assimilation of nitrate (Solomonson \& Barber 1990). All these and other related processes will naturally lead to poor plant growth and productivity.

Among the various compounds employed in order to alleviate plant stress, the brassinosteroids (BRs) are recognized as a novel group for regulating plant growth and productivity. Studies conducted to date have revealed that BRs elicit a wide range of various morphological and physiological responses in plants (Hayat et al. 2010a; Bajguz \& Hayat 2009). In addition, BRs are recognized as regulators of transcription and translation (Bajguz 2000), mechanisms by which they improve the levels of total proteins and enzymes (Fariduddin et al. 2004; Hasan et al. 2008), as well as increasing the seed yield at harvest (Fariduddin et al. 2004). The BRs not only play a regulatory role in plant growth but are also involved in establishing defense mechanisms to counter various biotic and abiotic stresses (Hayat et al. 2010a). However, it would be premature to assign specificity to their effects, under such conditions, before additional work is undertaken within this line of research.

Brassica juncea is an oil seed crop whose susceptibility to disease, salinity and drought results in poor growth and productivity. Therefore, the aim of this study was to explore one of those aspects: to identify remedial measures for overcoming the negative effects of salinity stress through BR treatment.

\section{Materials and methods}

The seeds of Brassica juncea Czern and Coss cv. Varuna, were surface sterilized with $5 \%$ sodium hypochlorite solution and washed repeatedly with double-distilled water. The seeds were immersed in water (controls) or in 50, 100 or $150 \mathrm{mM}$ of sodium chloride $(\mathrm{NaCl})$ for $6 \mathrm{~h}$ (duration based on the experience gained in earlier experiments). These treated seeds were subsequently sown in earthen pots ( $25 \mathrm{~cm}$ diameter) filled with sandy loam and farmyard manure mixed in a ratio of 9:1. Pots were irrigated regularly with tap water. Aqueous solutions of $10^{-6}, 10^{-8}$ or $10^{-10} \mathrm{M}$ of the BR 28-homobrassinolide (HBL) were applied to the leaves at 15,30 or 45 days after sowing (DAS). The plants were sampled at 60 DAS to assess leaf chlorophyll content,

\footnotetext{
${ }^{1}$ King Saud University, Department of Botany \& Microbiology, Saudi Arabia

${ }^{2}$ Author for correspondence: hayat_68@yahoo.co.in
} 
activities of carbonic anhydrase and nitrate reductase, rate of photosynthesis and leaf proline content. Mature plants were harvested at 140 DAS to assess seed yield. Each treatment was applied in quintuplicate. Chlorophyll content was estimated according to Mackinney (1941). Carbonic anhydrase and nitrate reductase activities were determined following the procedure of Dwivedi \& Randhawa (1974) and Jaworski (1971), respectively. The photosynthesis rate was measured in fully expanded leaves by a portable photosynthesis system (LI-6200; LI-COR, Lincoln, NE, USA). Leaf proline content was estimated following the method of Bates et al. (1973). The data were analyzed by ANOVA. Mean differences were compared by the least significant difference test, at a significance level of 5\% (Gomez \& Gomez 1984).

\section{Results and discussion}

At 60 DAS, the plants raised from the seeds exposed to pre-sowing soaking in $\mathrm{NaCl}$ (at 50, 100 or $150 \mathrm{mM}$ ), in comparison with those raised from the control seeds, showed lower chlorophyll content (Fig. 1), a lower photosynthesis rate (Fig. 1), less carbonic anhydrase activity (Fig. 2), less nitrate reductase activity (Fig. 2), and lower seed yield (Fig. 3), and higher proline content (Fig. 3). Moreover, the impact of the salinity stress became more pronounced as the concentration of $\mathrm{NaCl}$ was increased from 50 to $150 \mathrm{mM}$.
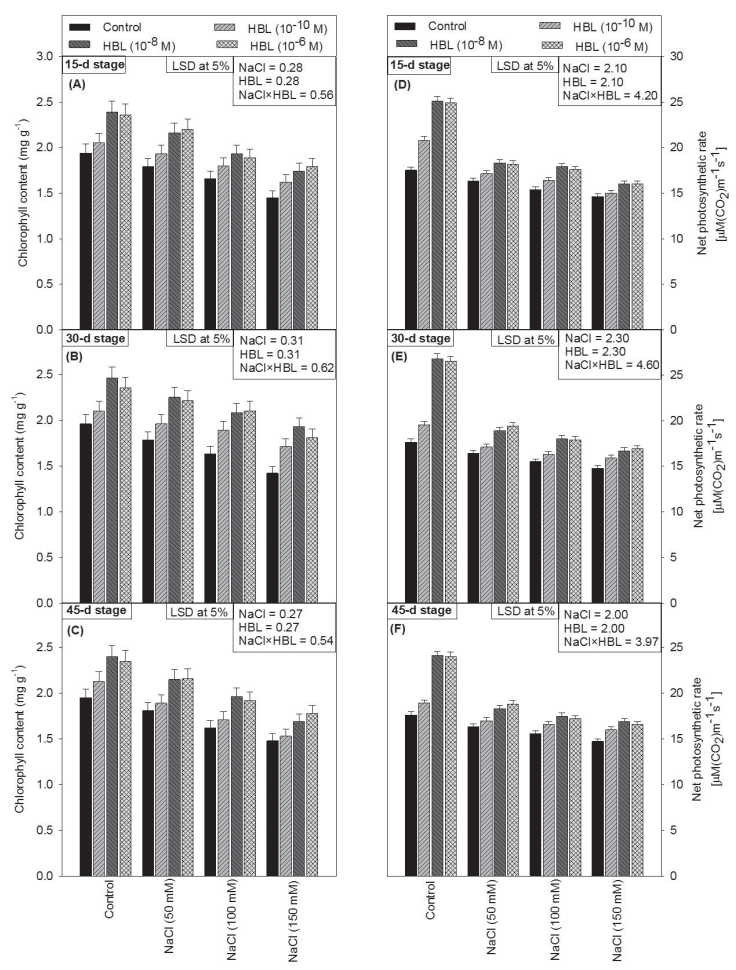

Figure 1. Effect of foliar application of 28-homobrassinolide (HBL) on the chlorophyll content $\left(\mathrm{mg} \mathrm{g}^{-1}\right)$ and photosynthesis rate $\left[\mu \mathrm{M}\left(\mathrm{CO}_{2}\right) \mathrm{m}^{-1} \mathrm{~S}^{-1}\right]$ in mustard plants under conditions of salinity, at 60 days after sowing.

- $\mathrm{d}$ - days (of application, $\mathrm{n}$ of days after sowing); LSD - least significant difference (test)
The activity of the enzyme chlorophyllase, which brings about the degradation of chlorophyll pigments, increases during salinity stress (Reddy \& Vora 1986). Therefore, the contents of the pigments exhibit a sharp decline as the salinity stress intensity increase (Zhao et al. 2007), as depicted in Fig. 1. The other enzyme, carbonic anhydrase, which determines the reversible interconversion of $\mathrm{CO}_{2}$ and $\mathrm{HCO}_{3}^{-}$, is regulated by photon flux density, $\mathrm{CO}_{2}$ concentration, availability of zinc (Tiwari et al. 2005) and the transcriptional state of the genes encoding its protein (Kim et al. 1994). In addition to other factors, salinity stress brings about the closure of stomata, thereby decreasing the partial pressure of $\mathrm{CO}_{2}$ (Soussi et al. 1998), as well as a drop in the activity of carbonic anhydrase (Fig. 2). The reported decrease in the activity of carbonic anhydrase by $\mathrm{NaCl}$ is in agreement with Hayat et al. (2010b). All of these restrictions (i.e., light harvesting centers and lower $\mathrm{CO}_{2}$ ) imposed by salinity stress have a direct impact on photosynthesis, the rate of which declines (Fig. 1). Nitrate $\left(\mathrm{NO}_{3}\right)$, the inorganic form of nitrogen that makes its way into the plants through the roots, has to be converted to its organic form $\left(\mathrm{NH}_{3}\right)$ before being incorporated into a keto acid. The nitrate reductase enzyme initiates the process of reducing $\mathrm{NO}_{3}$ to $\mathrm{NO}_{2}$, the very first step, which is found to be the limiting factor for the rest of the process. The nitrate reductase is induced to be synthesized by the substrate, which is $\mathrm{NO}_{3}$
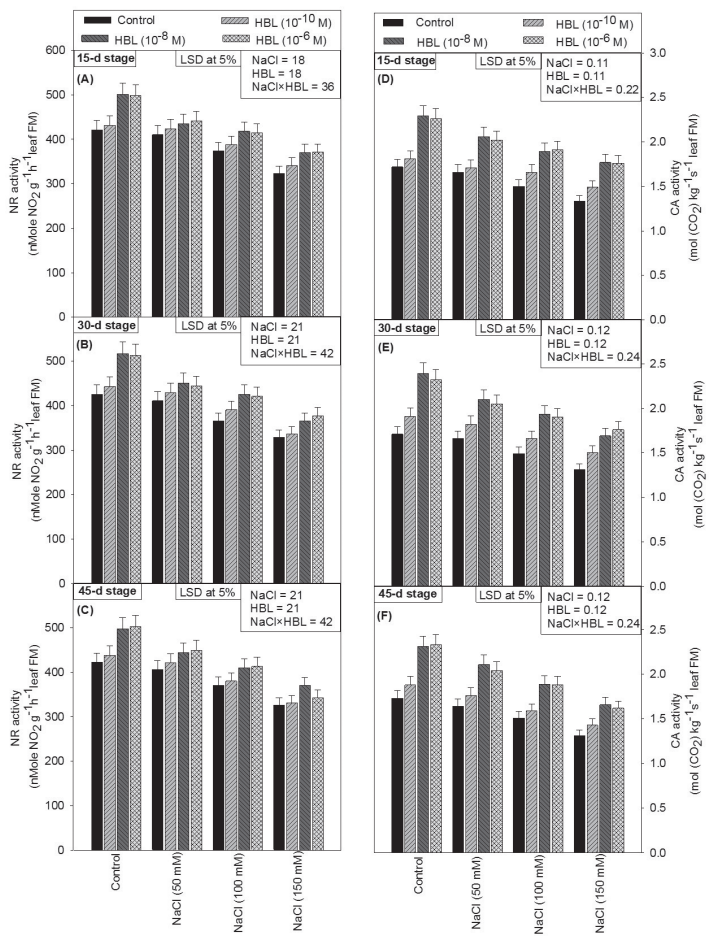

Figure 2. Effect of foliar application of 28-homobrassinolide (HBL) on nitrate reductase (NR) activity [n $\mathrm{M} \mathrm{NO}_{2} \mathrm{~g}^{-1} \mathrm{~h}^{-1}$ leaf f.m.) and carbonic anhydrase (CA) activity [ $\mathrm{mol}\left(\mathrm{CO}_{2}\right) \mathrm{kg}^{-1} \mathrm{~S}^{-1}$ leaf f.m.] in mustard plants under conditions of salinity, at 60 days after sowing.

- $\mathrm{d}$ - days (of application, $\mathrm{n}$ of days after sowing); LSD - least significant difference (test). 

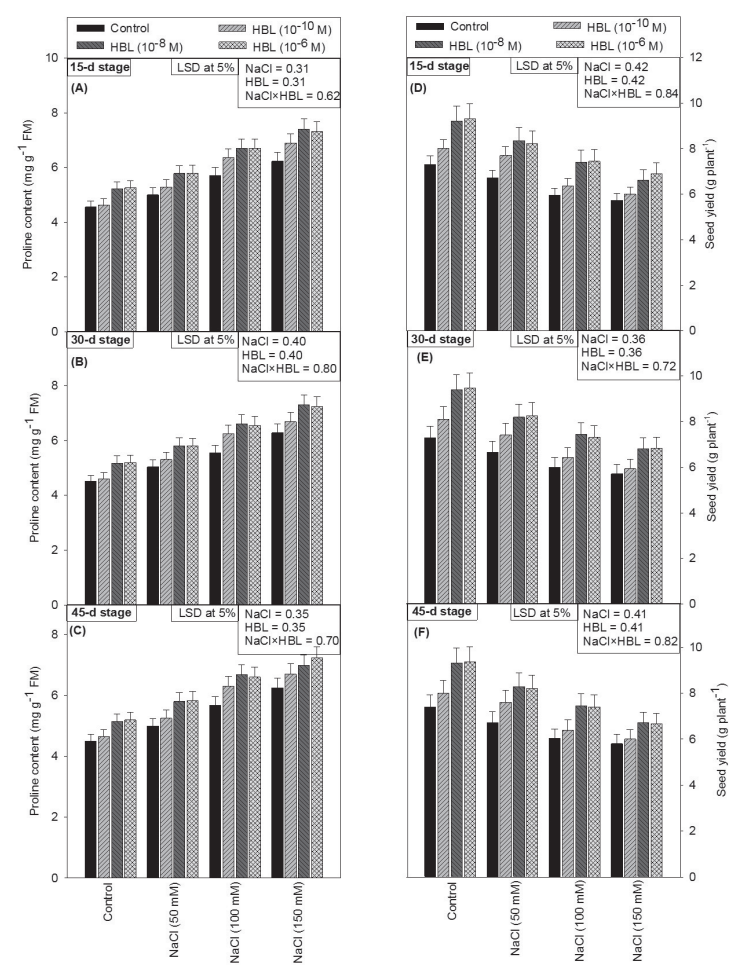

Figure 3. Effect of foliar application of 28 -homobrassinolide (HBL) on the proline content $\left(\mathrm{mg} \mathrm{g}^{-1} \mathrm{f} . \mathrm{m}\right.$.) at 60 days after sowing and seed yield $\left(\mathrm{g} \mathrm{plant}^{-1}\right)$ at 140 days after sowing (at harvest) in mustard plants under conditions of salinity. -d - days (of application, $\mathrm{n}$ of days after sowing); LSD - least significant difference (test).

(Solomonson \& Barber 1990), and its level is also affected by a number of internal and external factors (Campbell 1999). In the present study, the plants have been exposed to stress at the seed stage; therefore, the following are factors that could have changed the pattern of the inducibility of nitrate reductase in the plants: the competitive nature of the relationship between chloride ions and nitrate ions, which reduces the level of the inducer of nitrate reductase at the site of action; the fact that chloride ions act at the level of the membrane bound proteins to change the integrity of the plasma membrane (Cramer et al. 1985), imposing certain restrictions on the nitrate flux, resulting in the loss of the inducer and the enzyme protein (Solomonson \& Barber 1990); and the fact that stress-generated signals might act directly on the degradation or inactivation of the existing proteins or the repression of gene expression (Ferrario et al. 1998). The observed decrease (Fig. 2) in the level of nitrate reductase is, therefore, an expression of any one of those factors or a combination of multiple factors.

The stress-induced marker protein (proline) is produced from glutamate, catalyzed by $\Delta^{1}$-pyrroline-5-carboxylate synthase $\left(\Delta^{1} \mathrm{P}_{5} \mathrm{CS}\right)$ to $\Delta^{1}$-proline-5-carboxylate $\left(\mathrm{P}_{5} \mathrm{C}\right)$, which is subsequently converted to proline by the enzyme $\Delta^{1}$-pyrroline-5-carboxylate reductase $\left(\Delta^{1}-\mathrm{P}_{5} \mathrm{CR}\right)$. However, as the situation demands, proline may undergo degradation to $\mathrm{P}_{5} \mathrm{C}$ by proline dehydrogenase $(\mathrm{ProDH})$ and finally to glutamate by pyrroline-5-carboxylate dehydrogenase $\left(\mathrm{P}_{5}-\mathrm{CDH}\right)$ (Hong et al. 2000). A direct relationship between the metabolic and catabolic enzymes of the proline has been reported by Sumithra \& Reddy (2004) in cowpeas grown under water stress. They observed that the activity of the two enzymes $\left(\Delta^{1} \mathrm{P}_{5} \mathrm{CS}\right.$ and $\left.\Delta^{1} \mathrm{P}_{5} \mathrm{CR}\right)$ responsible for the synthesis of proline increased and that of ProDH simultaneously decreased. This relationship has been further explored, in transgenic plants, by Kishor et al. (1995), who identified a relationship between the increased activity of $\mathrm{P}_{5} \mathrm{CS}$ and a decrease in that of ProDH, with the overexpression of genes for the former and suppression for the latter. Proline accumulation is, therefore, a highly regulated phenomenon, determined by the genes. In the present study, the physiological drought caused by exposing the plants to $\mathrm{NaCl}$ (Hopkins 1995) activated the synthesis of proline and inhibited its degradation, resulting in higher proline levels in the tissues (Fig. 3). Similar observations were previously reported for Brassica juncea under salinity stress (Hayat et al.2010a). This higher proline level is somehow involved in the regulation of plant mechanisms of protection against the stress by restoring cell volume and turger; controlling damage by free radicals; and protecting/stabilizing enzymes and membrane structure (Timasheff \& Arakawa 1989).

Spraying the leaves of the plants with HBL improved the values for all of the parameters studied - in those raised from the seeds subjected to $\mathrm{NaCl}$ stress and in those raised from control seeds. This gives the impression that the hormone overrode the inhibitory effect of $\mathrm{NaCl}$, albeit to a limited extent, as determined by the concentration of $\mathrm{NaCl}$ and that of HBL. The best interaction between the HBL and the plants, if supplemented with either of the two higher concentrations $\left(10^{-8}\right.$ or $\left.10^{-6} \mathrm{M}\right)$, was observed at 60 DAS. Other plants have also been found to exhibit a similar response to BRs (Eleiwa et al. 2011; Yu et al. 2004). To improve the values for certain proteins, such as Rubisco (Yu et al. 2004), nitrate reductase (Fig. 2), carbonic anhydrase (Fig. 2), and proline (Fig. 3), BRs involve transcription, translation, or both (Bajguz 2000). It is of note that $\mathrm{HBL}$ and $\mathrm{NaCl}$ had a synergistic effect on proline content, thereby making the plants more tolerant to stress.

The productivity of any crop is determined by a number of factors borne within and without the plants, in particular water balance; nutrient availability; assimilation and translocation rates; hormonal balance; and life span of physiologically active photosynthesizing organs. In the present study, it was evident that certain physiological activities of the foliage have been retarded by the salinity stress (Fig. 1-3). In addition, stress is known to induce the synthesis of additional quantities of abscisic acid and ethylene (Nilsen \& Orcutt 1996), which disrupts the translocation of assimilates (Sultana et al. 1999) leading to plant senescence. However, as was observed here, the use of BRs, with or without salinity stress, not only has a constructive effect on the physiological activities of the plants but also extends 
the life span of the organs and facilitates the translocation of assimilates (Hayat et al. 2010a), thereby ameliorating the detrimental effect of salinity stress on the seed yield (Fig. 3). Our findings are in agreement with those of Eleiwa et al. (2011), who demonstrated that the seed yield of wheat and chickpea grown under $\mathrm{NaCl}$ stress was improved by BRs.

\section{Conclusion}

On the basis of our results, we can conclude that the foliar application of HBL improves crop performance and increases seed yield under salinity stress.

\section{Acknowledgments}

The authors would like to express their appreciation to the Deanship of Scientific Research at King Saud University for the funding provided (Group Research Project Grant no. RGP-VPP-199).

\section{References}

Aslam, M.; Huffaker, R.C. \& Rains, D.W. 1984. Early effects of salinity on nitrate assimilation in barley seedlings. Plant Physiology 76(2): 321-325.

Bajguz, A. 2000. Effect of brassinosteroids on nucleic acid and protein content in cultured cells of Chlorella vulgaris. Plant Physiology Biochemistry 38: 797-801.

Bajguz, A. \& Hayat, S. 2009. Effects of brassinosteroids on the plant responses to environmental stresses. Plant Physiology Biochemistry 47(1): 1-8.

Bates, L.S.; Waldeen, R.P. \& Teare, I.D. 1973. Rapid determination of free proline for water stress studies. Plant Soil 39: 205-207.

Campbell, H.W. 1999. Nitrate reductase structure, function and regulation. Bridging the gap between biochemistry and physiology. Annual Review of Plant Physiology and Plant Molecular Biology 50: 277-303.

Chaves, M.M.; Flexas, J. \& Pinheiro, C. 2009. Photosynthesis under drought and salt stress: Regulation mechanism of whole plant to cell. Annals of Botany 103: 551-568.

Cramer, G.R.; Lauchli, A. \& Polito, V.S. 1985. Displacement of $\mathrm{Ca}^{2+}$ by $\mathrm{Na}^{2+}$ from the plasmalemma of root cells. A primary response of salt stress. Plant Physiology 79: 207-277.

Dwivedi, R.S. \& Randhawa, N.S. 1974. Evaluation of a rapid test for the hidden hunger of zinc in plants. Plant Soil 40: 445-451.

Eleiwa, M.E.; Bafeel, S.O. \& Ibrahim, S.A. 2011. Influence of brassinosteroids on wheat plant (Triticum aestivum L.). Australian Journal of Basic and Applied Sciences 5(5): 49-57.

Fariduddin, Q.; Ahmad, A. \& Hayat, S. 2004. Response of Vigna radiata to foliar application of 28-homobrassinolide and kinetin. Biologia Plantarum 48: 465-468.

Ferrario, S.; Valadier, M. \& Foyer, C.H. 1998. Overexpression of nitrate reductase in tobacco delays drought-induced decreases in nitrate reductase activity and mRNA. Plant Physiology 117: 293-302.
Gomez, K.A. \& Gomez, A.A. 1984. Statistical procedures for agricultural research 2nd ed. New York, John Wiley and Sons.

Hasan, S.A.; Hayat, S.; Ali, B. \& Ahmad, A. 2008. 28-Homobrassinolide protects chickpea (Cicer arietinum) from cadmium toxicity by stimulating antioxidant. Environmental Pollution 151: 60-66.

Hayat, S.; Mori, M.; Fariduddin, Q.; Bajguz, A. \& Ahmad, A. 2010a. Physiological role of brassinosteroids: An update. Indian Journal of Plant Physiology 15(2): 99-109.

Hayat, S.; Yadav, S.; Wani, A.S.; Irfan, M. \& Ahmad, A. 2010b. Response of tomato to two possible modes of salinity stress-a comparative analysis. Journal of Soil Salinity and Water Quality 2(2): 84-90.

Hong, Z.; Kakkineni, K.; Zhang, Z. \& Verma, D.P. 2000. Removal of feedback inhibition of $\mathrm{D}^{1}$-pyrroline-5-carboxylate synthetase results in increased accumulation and protection of plants from osmotic stress. Plant Physiology 122: 1129-1136.

Hopkins, W.J. 1995. Introduction to Plant Physiology. New York, John Wiley and Sons Inc

Jaworski, E.G. 1971. Nitrate reductase assay in intact plant tissues. Biochemistry Biophysics Research Communication 43: 1274-1279.

Kim, H.J.; Bracey, M.H. \& Barlett, S.G. 1994. Nucleotide sequence of a gene encoding carbonic anhydrase in Arabidopsis thaliana. Plant Physiology 105: 449.

Kishor, P.; Hong, Z.; Miao, G.H.; Hu, C. \& Verma, D. 1995. Overexpression of [delta]-Pyrroline-5-Carboxylate Synthetase Increases Proline Production and Confers Osmotolerance in Transgenic Plants. Plant Physiology 108(4): 1387-1394.

Koca, M.; Bor, M.; Ozdemir, F. \& Turkan, I. 2007. The effect of salt stress on lipid peroxidation antioxidative enzymes and proline content of sesame cultivars. Environmental and Experimental Botany 60: 344-351.

Mackinney, G. 1941. Absorption of light by chlorophyll solutions. Journal of Biological Chemistry 140: 315-322.

Nilsen, E.T. \& Orcutt, D.M. 1996. Phytohormones and plant responses to stress. Pp.83-198. In: Nilsen, E.T. \& Orcutt, D.M. (Eds.), Physiology of plant under stress. New York, John Wiley and Sons, Inc.

Reddy, M.P. \& Vora, A.B. 1986. Changes in pigment composition, hill reaction activity and saccharide metabolism in bajra (Pennisetum typhoides S\&H) leaves under $\mathrm{NaCl}$ salinity. Photosynthetica 20: 50-55.

Solomonson, L.P. \& Barber, M.J. 1990. Assimilatory nitrate reductase. Functional properties and regulation. Annual Review of Plant Physiology and Plant Molecular Biology 41: 225-253.

Soussi, M.; Ocana, A. \& Lluch, C. 1998. Effect of salt stress on growth, photosynthesis and nitrogen fixation in chickpea (Cicer arietinum $\mathrm{L}$.) Journal of Experimental Botany 49: 1329-1337.

Sultana, N.; Ikeda, T. \& Itoh, R. 1999. Effect of $\mathrm{NaCl}$ salinity on photosynthesis and dry matter accumulation in developing rice grains. Environmental and Experimental Botany 42: 211-220.

Sumithra, K. \& Reddy, A.R. 2004. Changes in proline metabolism of cowpea seedlings under water deficit. Journal of Plant Biology 31: 201-204.

Timasheff, S.N. \& Arakawa, T. 1989. Stabilization of protein structure by solvents. Pp. 331-334. In: Creigton, T.E. (Ed.), Protein structure. A practical approach. Oxford, IRL Press.

Tiwari, A.; Kumar, P.; Singh, S. \& Ansari, S.A. 2005. Carbonic anhydrase in relation to higher plants. Photosynthetica 43: 1-9.

Yu, J.Q.; Huang, L.F.; Hu, W.H.; Zhou, Y.H.; Mao, W.H.; Ye, S.F. \& Nogues, S. 2004. A role of brassinosteroids in the regulation of photosynthesis in Cucumis sativus. Journal of Experimental Botany 55: 1135-1143.

Zhao, J.; Ren, W.; Zhi, D.; Wang, L. \& Xia, G. 2007. Arabidopsis DREB1A/ $\mathrm{CBF} 3$ bestowed transgenic tall rescue increased tolerance to drought stress. Plant Cell Reports 26: 1521-1528. 